\title{
Pilinan Bambu sebagai Alternatif Pengganti Tulangan Tarik pada Balok Beton
}

\author{
Endang Kasiati, Boedi Wibowo \\ Staft Pengajar Program Studi DiplomaTeknik Sipil FTSP ITS \\ Email: en_kas@ce.its.ac.id, boewi_boy@ce.its.ac.id
}

\begin{abstract}
ABSTRAK
Baja tulangan adalah produk olahan hasil tambang yang akan habis. Sebagai alternatif dicoba pemakaian tulangan bambu yang murah dan berkekuatan tinggi. Penelitian ini akan membandingkan kuat tarik Bambu Apus/Tali, Bambu Ori, dan Bambu Jawa/Kèlès yang sudah dipilin dengan tegangan leleh baja tulangan mutu U-22. Bambu akan diambil bagian kulitnya, dengan dimensi $1 \times 3 \times 750 \mathrm{~mm}$. Bagian kulit diambil tiga helai dan dipilin, kemudian 15 pilinan disatukan dengan kawat bendrat sepanjang pilinan bambu dengan jarak $20 \mathrm{~mm}$. Lalu, dilakukan uji kuat tarik dengan acuan tegangan leleh baja tulangan mutu U-22 pada PBBI 1971. Pilinan bambu jenis yang paling kuat akan diaplikasikan pada

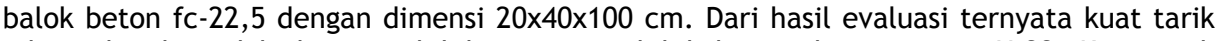
pilinan bambu tidak dapat melebihi tegangan leleh baja tulangan mutu U-22. Kuat tarik pilinan bambu rata-rata terbesar adalah $1.989,97 \mathrm{~kg} / \mathrm{cm}$, lebih kecil $9,55 \%$ dari baja mutu U-22, yaitu dari bambu jenis Apus. Gaya lentur yang dihasilkan dari balok bertulangan pilinan bambu apus lebih besar 75,49 \% dari hasil perhitungan balok normal secara teoritis menggunakan tegangan baja.
\end{abstract}

Kata kunci : bambu, kuat tarik, balok, gaya lentur

\section{PENDAHULUAN}

Baja tulangan adalah produk olahan hasil tambang yang keberadaannya suatu saat akan habis, sehingga akan membuat harga baja akan melambung tinggi. Salah satu alternatif agar nilai ekonomis bahan dalam perencanaan struktur gedung dapat tercapai adalah menggunakan bambu sebagai pengganti tulangan baja tarik. Bambu dikenal memiliki sifat-sifat yang baik untuk dimanfaatkan sebagai pengganti tulangan baja tarik, antara lain batangnya kuat, ulet, lurus, rata, keras, mudah dibelah, mudah dibentuk dan mudah dikerjakan serta ringan, sehingga mudah diangkut. Selain itu bambu juga relatif murah dibandingkan dengan bahan bangunan lain karena banyak ditemukan di sekitar pemukiman pedesaan. Pada penelitian ini, bambu galah digunakan sebagai tulangan balok beton, dimana balok direncanakan bertulangan liat (underreinforced) dan tidak bertulangan tekan, semua balok diberi tulangan bambu pilinan dengan diameter $12 \mathrm{~mm}$ dan diberi lapisan kedap air. Perbaikan kuat lekat dilakukan dengan cara bambu divernis ataupun bambu dipilin [1]. Langkah awal dalam penelitian ini adalah menentukan jenis bambu yang akan dipakai. Bambu yang dipakai pada penelitian ini adalah Bambu Apus/Tali Gigantochloa apus Kurz), Bambu Ori, dan Bambu Jawa/Kèlès. Menurut situs internet dengan alamat www.dephut.go.id (tentang penelitian bambu) Bambu Apus/Tali kuat terhadap tarik, terutama kulit bambu yang merupakan pelindung dan bagian terkuat dari bambu [2]. Selain itu, bambu ini juga mudah dilenturkan dibanding bambu jenis lain, tahan lama sekalipun tanpa pengawetan, dan mudah didapatkan. Sedangkan alasan memilih Bambu Ori dan Bambu Jawa adalah karena bambu tersebut banyak ditemui di pasaran, khususnya diSurabaya sendiri. Bambu Ori biasa digunakan sebagai gedek atau bilik bambu, atau untuk membuat rumah sederhana. Bambu Jawa biasa digunakan untuk tiang bendera sederhana atau tiang untuk umbulumbul.Bambu akan diambil bagaian kulitnya dan dipilin, kemudian dilakukan test tarik pilinan bambu Apus, bambu Ori dan bambu Jawa. Selanjutnya dipilih jenis pilinan bambu yang paling kuat dan diaplikasikan sebagai tulangan pada balok beton fc-22,5 
dengan demensi $(20 \times 40 \times 100) \quad \mathrm{cm} \quad$ [1]. Dilakukan juga peninjauan terhadap sifat Fisis Mekanis Bambu Hitam dan Bambu Apus, sehingga mengetahui keteguhan tarik dan keteguhan tekan sejajar serat, untuk dibandingkan dengan keteguhan tarik pilinan bambu. Selanjutnya dilakukan Mix Design
Beton dengan perbandingan Volume material Beton yang telah diperhitungkan, kemudian dilakukan uji kuat lentur pada balok. Diharapkan akan didapat jenis pilinan bambu yang paling kuat sehingga dapat diaplikasikan pada balok beton [3].

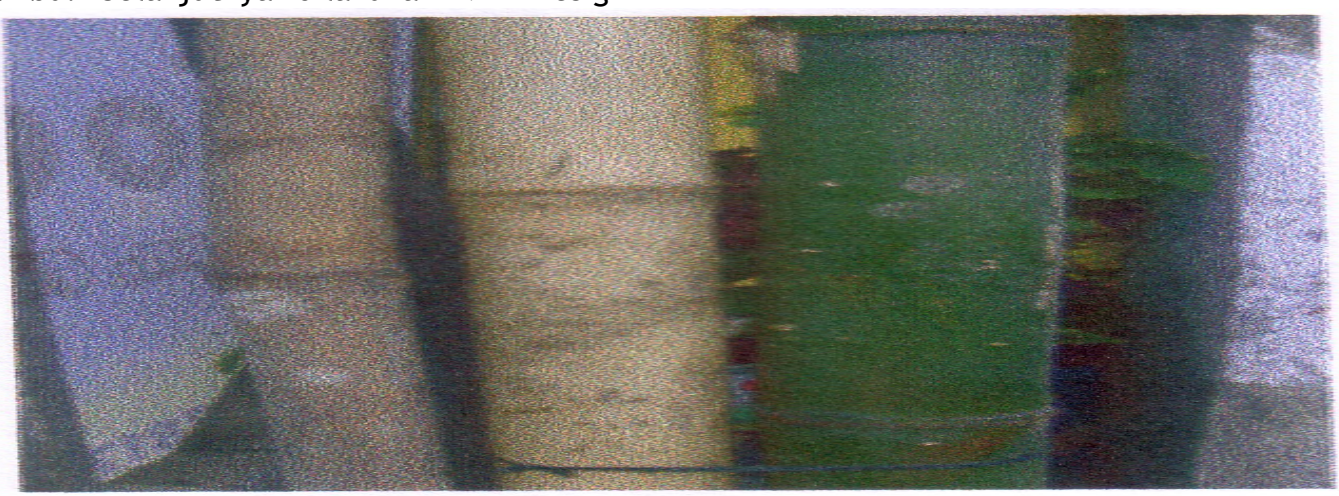

Gambar 1. Bambu Apus,Bambu Jawa, Bambu Ori [2]

\section{METODOLOGI}

Prosedur pelaksanaan penelitian dimulai dari persiapan pengambilan bahan baku antara lain: Bambu Ori, Bambu Apus dan Bambu Jawa, pasir, kerikil, Semen Portland dan air PDAM. Selanjutnya dilakukan uji fisik Pasir, Kerikil dan Semen Portland [4], kemudian dilakukan pengambilan kulit bambu tebal $1 \mathrm{~cm}$ lebar $3 \mathrm{~cm}$ dan panjang 75 $\mathrm{cm}$ lalu dipilin dan pilinan bambu tersebut dikeringkan dipanas matahari selama 7 hari.
Dibuat masing-masing 3 tulangan dari 5 pilinan bambu Ori, Apus dan Jawa dengan diikat memakai kawat bendrat lalu dilakukan test tarik untuk menentukan jenis pilinan bambu yang mana yang paling kuat. Kemudian dibuat balok beton dengan tulangan bambu untuk dilakukan test lentur [3] dan hasilnya dibandingkan dengan balok beton teoritis. Secara singkat dapat dilihat pada bagan alur dibawah ini : 


\section{ISSN.1907-753X}

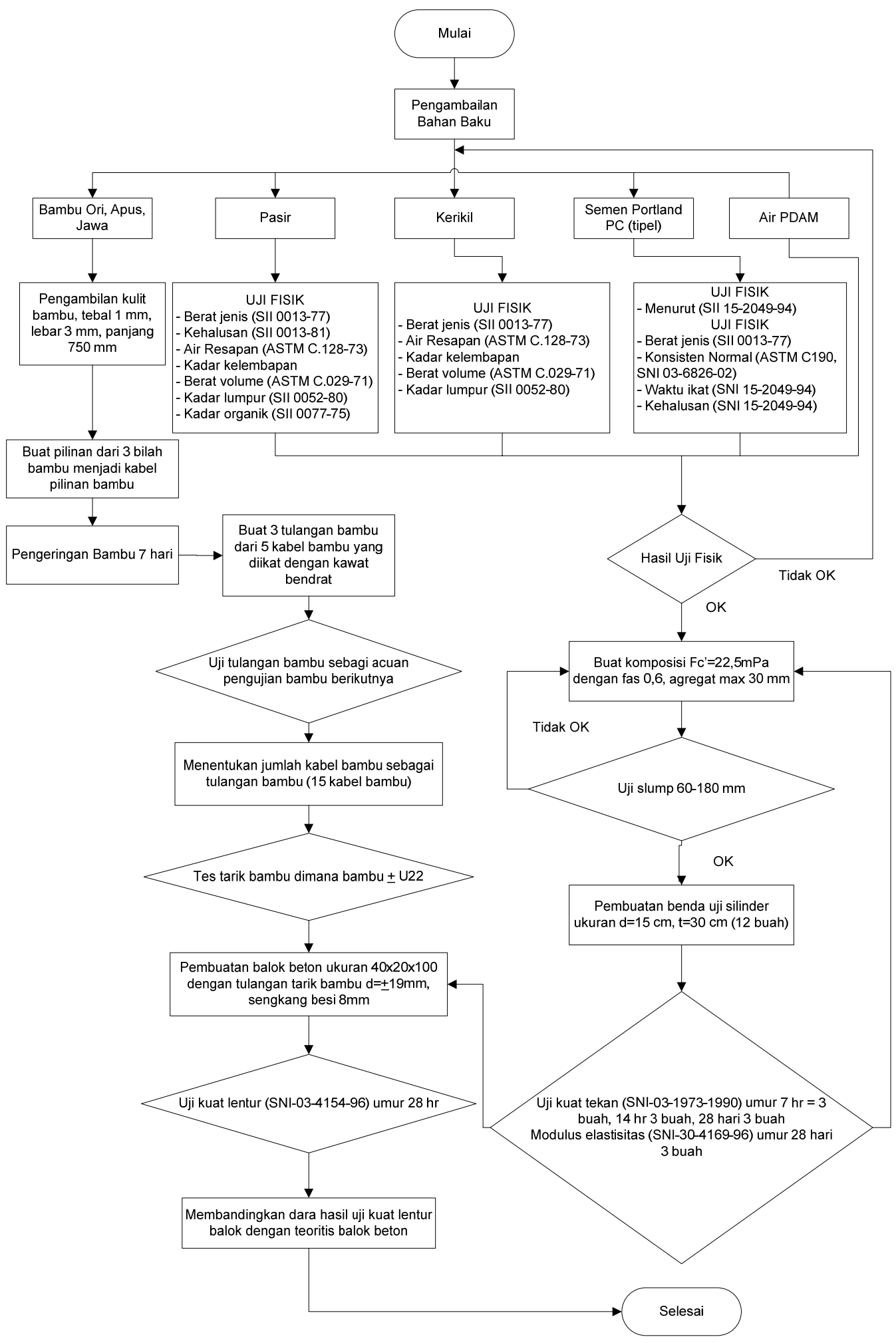

Gambar 2. Bagan Alur Pembuatan Balok Beton dengan Tulangan Bambu 


\subsection{Pengambilan Bahan Baku}

\section{Bambu Apus/Bambu Tali (Gigantochloa apus Kurz) [2]}

Bambu Apus/Bambu Tali didatangkan dari Madura. Hal ini dikarenakan bambu jenis ini sulit didapatkan di daerah Surabaya. Selain di daerah Madura juga bisa didapatkan didaerah Sidoarjo dan Tulungagung, sebenarnya tidak sulit untuk mengembangbiakkan bambu jenis ini, hanya saja di daerah perkotaan dianggap kurang berguna karena bambu jenis ini biasanya digunakan untuk kerajinan tangan di daerah pedesaan. Bambu yang dipakai dipilih yang berusia \pm 12 bulan dikarenakan bambu pasaran kebanyakan berusia \pm 12 bulan.

Karakteristik bambu ini adalah :

a. Habitus : pohon, berumpun, tinggi 10 $15 \mathrm{~m}$

b. Batang : berkayu, bulat, berlubang beruas-ruas, tunas atau rebung berbulu, putih kehitaman, hijau

c. Daun : runcing, tepi rata, pangkal membulat, panjang $20-30 \mathrm{~cm}$, lebar 4$6 \mathrm{~cm}$, pertulangan sejajar, hijau

d. Akar : serabut, putih kotor

\section{Bambu Ori [2]}

Bambu Ori mudah didapatkan di pasaran. DiSurabaya banyak penjual bambu yang menjualnya. Bambu yang dipakai dipilih yang berusia \pm 12 bulan dikarenakan bambu potongan di pasaran kebanyakan berusia \pm 12 bulan. Karakteristik bambu ini adalah :

potongan di pasaran kebanyakan berusia \pm 12 bulan.

a. Habitus : pohon, berumpun, tinggi 10 $12 \mathrm{~m}$

b. Batang : berkayu, bulat, berlubang, beruas-ruas, tunas atau rebung berbulu, hijau tua, ranting berduri

c. Daun : runcing, tepi rata, pangkal membulat, panjang $10-15 \mathrm{~cm}$, lebar 3 $5 \mathrm{~cm}$, pertulangan sejajar, hijau

d. Akar : serabut, putih kotor

Bambu J awa/Bambu Kèlès [2]

Bambu Jawa/Bambu Kèlès mudah didapatkan dipasaran. Di Surabaya banyak penjual bambu yang menjualnya. Bambu yang dipakai dipilih yang berusia \pm 12 bulan dikarenakan bambu potongan di pasaran kebanyakan berusia \pm 12 bulan. Karakteristik bambu ini adalah :

a. Habitus : pohon, berumpun, tinggi 10$13 \mathrm{~m}$

b. Batang : berkayu, bulat, berlubang, beruas-ruas, tunas atau rebung berbulu, hijau tua kekuningan

c. Daun : runcing, tepi rata, panjang 20$30 \mathrm{~cm}$, lebar 4-6 cm, pertulangan sejajar, hijau, kasar

d. Akar : serabut, putih kotor

\subsection{Persiapan dan Pembuatan Benda Uji}

Bambu adalah sejenis tanaman yang dikenal masyarakat memiliki sifat - sifat yang baik untuk dimanfaatkan, antara lain batangnya kuat, ulet, lurus, rata, keras, mudah dibelah, mudah dibentuk dan mudah dikerjakan serta ringan, sehingga mudah diangkut. Bambu berbentuk bulat sehingga dapat dipakai untuk berbagai macam konstruksi seperti rumah, gudang, jembatan, tangga, pipa saluran air, dan lain - lain. Bambu adalah tanaman termasuk Bamboidae, salah satu anggota sub familia rumput, pertumbuhannya sangat cepat. Pada masa pertumbuhan, bambu tertentu dapat tumbuh vertikal 5 $\mathrm{cm}$ per jam, atau $120 \mathrm{~cm}$ per hari. Tanaman bambu mempunyai ketahanan yang luar biasa. Rumput bambu yang telah dibakar masih dapat tumbuh lagi. Bambu dapat tumbuh dilahan yang sangat kering seperti di kepulauan Nusa Tenggara atau dilahan yang banyak disirami air hujan seperti Parahiyangan. Di dunia tercatat lebih dari 75 genus dan 1250 spesies bambu. Bambu yang ada di Asia Selatan dan Asia Tenggara kira-kira 80\% dari keseluruhan yang ada di dunia. Genus Bambusa mempunyai jumlah spesies yang paling banyak, dan terutama banyak terdapat di daerah tropis, terutama Indonesia. Bambu, memiliki berat jenis yang berkisar antara $600-900 \mathrm{~kg} / \mathrm{m}^{3}$. Untuk jenis bambu tali memiliki berat jenis ratarata $820 \mathrm{~kg} / \mathrm{m}^{3}$. Bambu yang diteliti hanya Bambu Apus, Bambu Ori, dan Bambu Jawa. Pengeringan bambu menggunakan panas sinar matahari selama 7 (tujuh) hari. Pemisahan kulit bambu dari daging bambu dan pemilinan dilakukan secara manual, yaitu memakai tenaga manusia. Uji kuat tarik dilakukan sebatas pada 15 pilinan

Halaman 12 J urnal APLIKASI: Media Informasi \& Komunikasi Aplikasi Teknik Sipil Terkini 


\section{ISSN. 1907-753X}

bambu. Bambu akan diambil bagian panjang $75 \mathrm{~cm}$ bagaian ini relatif cukup padat sehingga sifat higroskopisnya rendah dan kurang memerlukan lapisan kedap air. Bagian kulit adalah bagian yang terkuat. Hasil penelitian menunjukkan kuat tarik bambu bagian luar kuranglebih tiga kali kuat tarik bagian dalam. Bagian kulit bambu tersebut dambil tiga helai dan dipilin, kemudian 15 pilinan kulit bambu disatukan menggunakan kawat bendrat yang dipasang di sepanjang pilinan bambu dengan jarak $20 \mathrm{~mm}$. Sebelum disatukan, bambu akan dikeringkan sehingga bambu menjadi lebih keras dan kaku. Pengeringan dilakukan secara tradisional, yaitu dijemur di bawah sinar matahari selama 7 hari. Setelah itu dilakukan uji kuat tarik dengan tiga kali pengetesan pada satu jenis pilinan bambu, pengujian ini dilakukan dengan acuan tegangan leleh baja tulangan mutu U-22 pada Peraturan Beton Bertulang Indonesia 1971 [5]. Pembuatan benda uji balok dibuat hanya satu buah. Langkah selanjutnya adalah menentukan bambu jenis apakah yang paling tinggi kuat tariknya sehingga dapat menjadi pengganti tulangan baja tarik. Menentukan jumlah pilinan bambu yang akan disatukan sehingga bisa mendapatkan kuat tarik yang kulitnya, setebal $\pm 1 \mathrm{~mm}$, lebar $3 \mathrm{~cm}$ dan kurang lebih sama dengan tegangan leleh baja tulangan mutu U-22. Mengetahui mampu atau tidak, pilinan bambu terkuat menggantikan tulanggan tarik dengan cara mengaplikasikan tulangan kabel pilinan bambu sebagai tulangan tarik pada balok beton fc-22,5. Setelah diketahui jenis pilinan bambu yang paling kuat, maka pilinan bambu jenis itu akan diaplikasikan pada balok beton fc-22,5 dengan dimensi $(20 \times 40 \times 100 \mathrm{~cm})$.

Kemudian akan dilakukan uji kuat lentur pada balok [4]. Pengujian dilakukan sehingga dipenuhi besar gaya lentur $(P)$ yang sama atau lebih besar dari nilai gaya lentur (P) yang diperoleh dari hasil perhitungan momen secara teoritis, yaitu : $M=\left(1 / 8 \mathrm{qL}^{2}\right)+(1 / 4 \mathrm{PL})[6]$

Pada akhirnya diharapkan didapatkan jenis pilinan bambu yang paling kuat dan dapat diaplikasikan pada balok beton. Dengan berhasilnya penelitian ini, akan didapatkan suatu cara untuk mendapatkan nilai yang lebih ekonomis dalam suatu struktur bangunan, ini dikarenakan harga bambu yang relatif murah dan berkurangnya penggunaan baja yang harganya relatif mahal.

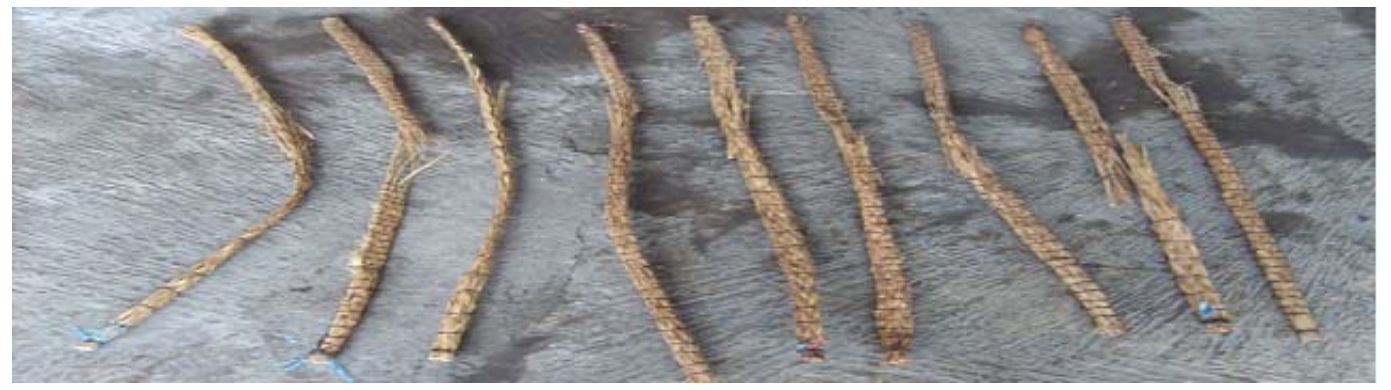

Gambar 3. Benda Uji Pilinan Bambu 
Tabel 1. Hasil Pengujian Sifat Fisis Mekanis Bambu Hitam dan Bambu Apus : [4]

\begin{tabular}{|c|c|c|c|}
\hline No. & Sifat & Bambu Hitam & Bambu Apus \\
\hline & Keteguhan lentur static & & \\
\hline \multirow[t]{5}{*}{1.} & a. Tegangan pada batas proporsi $(\mathrm{kg} / \mathrm{cm} 2)$ & 447 & 327 \\
\hline & b. Tegangan pada batas patah $(\mathrm{kg} / \mathrm{cm} 2)$ & 663 & 546 \\
\hline & c. Modulus elastisitas (kg/cm2) & 99000 & 101000 \\
\hline & d. Usaha pada batas proporsi $(\mathrm{kg} / \mathrm{dcm} 3)$ & 1,2 & 0,8 \\
\hline & e. Usaha pada batas patah $(\mathrm{kg} / \mathrm{dm} 3)$ & 3,6 & 3,3 \\
\hline \multirow[t]{2}{*}{2.} & Keteguhan tekan sejajar serat & 489 & 504 \\
\hline & (tegangan maximum, kg/cm2) & & \\
\hline 3. & Keteguhan geser $(\mathrm{kg} / \mathrm{cm} 2)$ & 61,4 & 39,5 \\
\hline 4. & Keteguhan tarik tegak lurus serat $(\mathrm{kg} / \mathrm{cm} 2)$ & 28,7 & 28,3 \\
\hline 5. & Keteguhan belah $(\mathrm{kg} / \mathrm{cm} 2)$ & & \\
\hline \multirow[t]{5}{*}{6.} & Berat jenis & & \\
\hline & a. KA pada saat pengujian & 0,83 & 0,69 \\
\hline & & $\mathrm{KA}: 28 \%$ & $\mathrm{KA}: 19,11 \%$ \\
\hline & b. KA kering tanur & 0,65 & 0,58 \\
\hline & & $\mathrm{KA}: 17 \%$ & $\mathrm{KA}: 16,42 \%$ \\
\hline \multirow[t]{4}{*}{7.} & Keteguhan pukul & & \\
\hline & a. Pada bagian dalam $(\mathrm{kg} / \mathrm{dm} 3)$ & 32,53 & 45,1 \\
\hline & b. Arah tangensial $(\mathrm{kg} / \mathrm{dm} 3)$ & 31,76 & 31,9 \\
\hline & c. Pada bagian luar (kg/dm3) & 17,23 & 31,5 \\
\hline
\end{tabular}

Sumber : Ginoga (1977)

\subsection{Evaluasi Hasil Pengujian di Laboratorium}

Hasil pengujian Sifat Fisis Mekanis Bambu Apus dapat dilihat pada tabel 1 mempunyai kuat tarik tegak lurus serat sebesar $28,3 \mathrm{~kg} / \mathrm{cm}^{2}$, setelah dilakukan pilinan bambu Apus mempunyai kuat tarik rata-rata 1989,97 kg/ $\mathrm{cm}^{2}$. Kenyataan ini menunjukkan bahwa pilinan bambu Apus mempunyai kekuatan tarik 70,32 kali lebih besar. Atas dasar ini maka dilakukan pilinan bambu sebagai alternative tulangan baja dan dilakukan test tarik seperti pada gambar 2 diatas. Selanjutnya kita tinjau hasil uluran pilinan Bambu Jawa, Bambu Ori dan Bambu Apus terhadap beban tarik seperti pada grafik (2),(3),(4) dan ternyata Bambu Apus mempunyai kuat tarik yang paling tinggi. Kemudian pilinan bambu jenis ini diaplikasikan pada balok beton fc22,5 dan dilakukan test lentur dilaboratorium,dari hasil kuat lentur balok beton dapat dilihat pada table 4 mempunyai $\mathrm{P}=22.450 \mathrm{~kg}$ dan hasil $\mathrm{P}$ menggunakan tegangan baja 12.792,82 kg sedangkan hasil $\mathrm{P}$ menggunakan tegangan bambu 11.611,54 kg. karena dari hasil praktek modulus elastisitas baja adalah 182.892 MPa sedangkan modulus elastisitas bambu adalah 77.130,27 MPa dimana modulus elastisitas baja mempunyai korelasi 0,9 dan bambu mempunyai korelasi 0,8 perbedaan modulus elastisitasnya adalah $10 \%$,hal ini berarti bambu dapat digunakan sebagai pengganti baja. Sedangkan hasil kuat tekan silinder umur 28 hari pada tabel 3 sebesar 230,24 $\mathrm{kg} / \mathrm{cm}^{2}$ memenuhi kuat tekan rencana yaitu $225 \mathrm{~kg} / \mathrm{cm}^{2}$. 


\section{ISSN. 1907-753X}

Tabel 2. Hasil Uji Kuat Tarik Pilinan Bambu

\begin{tabular}{|c|c|c|c|}
\hline Kode & Beban Tarik (kg) & Kuat Tarik (kg/cm² & $\begin{array}{c}\text { Kuat Tarik Rata- } \\
\text { Rata (kg/cm }\end{array}$ \\
\hline Jawa I & 1,800 & 1356.80 & \multirow{2}{*}{1432.18} \\
\hline Jawa II & 2,010 & 1515.09 & \\
\hline Jawa III & 1,890 & 1424.64 & \multirow{2}{*}{1507.56} \\
\hline Ori I & 1,800 & 1356.80 & \\
\hline Ori II & 2,310 & 1741.23 & \multirow{2}{*}{1989.97} \\
\hline Ori III & 1,890 & 1424.64 & \\
\hline Apus I & 2,640 & 1989.97 & \\
\hline Apus II & 2,490 & 1876.91 & \\
\hline Apus III & 2,790 & 2103.04 & \\
\hline
\end{tabular}

Pengujian dilakukan diLaboratorium Uji Beton S1 Teknik Sipil, FTSP ITS

Hasil Uluran Pilinan Bambu Jawa, Ori dan Apus terhadap Beban Tarik seperti pada grafik berikut:

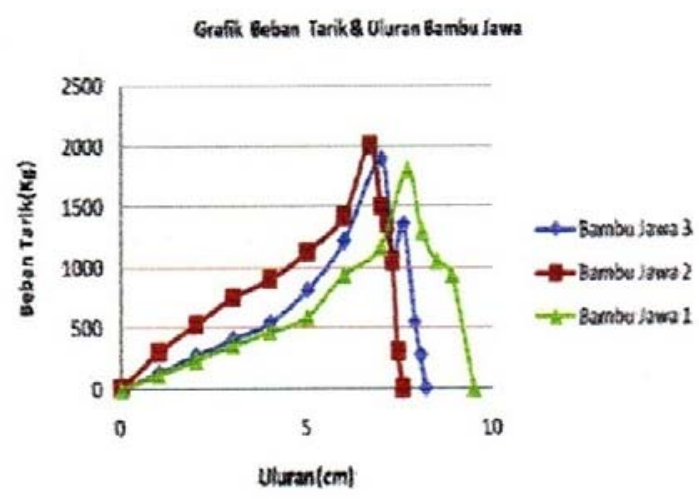

Gambar 4. Grafik Beban Tarik dan Ukuran Bambu Tali

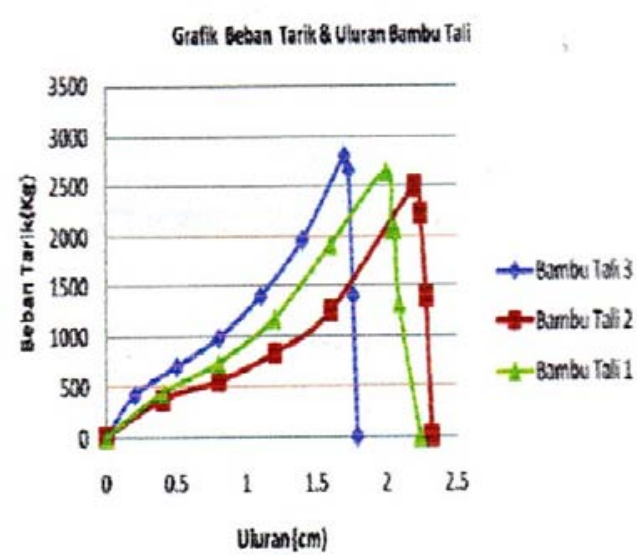

Gambar 6. Hubungan Beban Tarik dan Uluran Pilinan Bambu Apus
Grafik Beban Tarik \& Uluran Bambv Ori

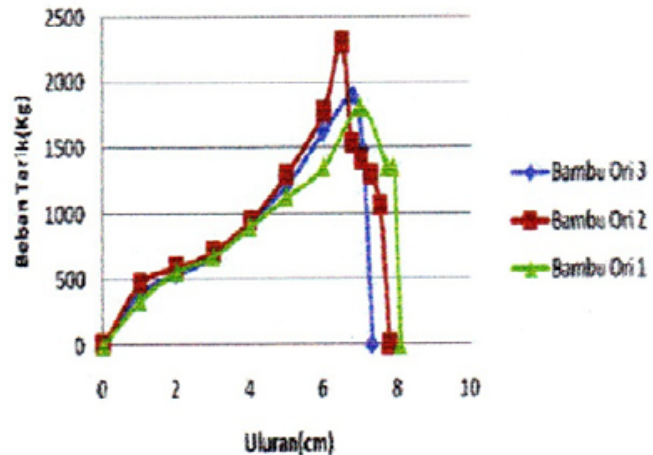

Gambar 5. Grafik Beban Tekan dan Penurunan Silinder

Grafik Beben Tekan dan Penurunan Sĭnder

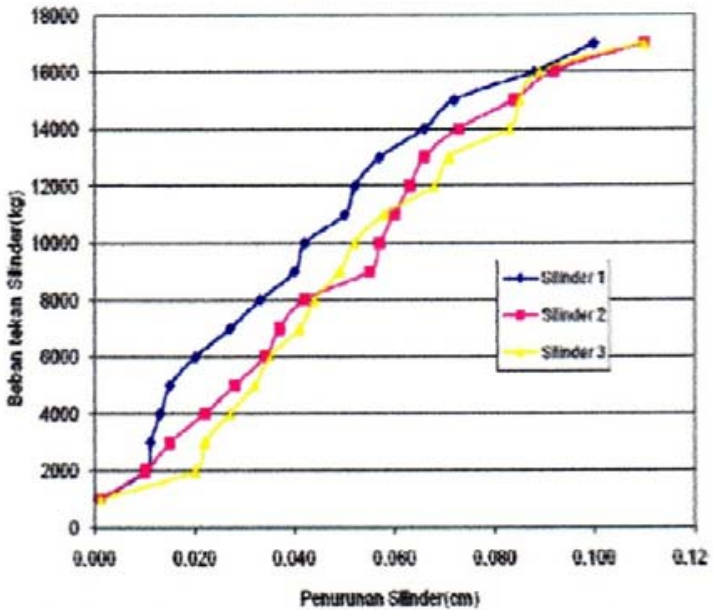

Gambar 7. Penurunan (Displacement) Silinder Umur 28 Hari pada Uji Modulus Elastisitas 
Tabel 3. Hasil Uji Kuat Tekan Silinder Rata-Rata Umur 7,14,28 Hari adalah sebagai berikut:

\begin{tabular}{|c|c|c|c|c|c|c|}
\hline MUTU & $\begin{array}{l}\text { UMUR } \\
\text { (Hari) }\end{array}$ & JUMLAH & $\begin{array}{c}\text { BERAT } \\
(\mathrm{kg})\end{array}$ & $\begin{array}{l}\text { BEBAN } \\
\text { HANCUR } \\
\text { (Ton) }\end{array}$ & $\begin{array}{c}\text { KUAT TEKAN } \\
\left(\mathrm{Kg} / \mathrm{cm}^{2}\right)\end{array}$ & $\begin{array}{c}\text { KUAT TEKAN } \\
\text { RATA-RATA } \\
\left(\mathrm{Kg} / \mathrm{cm}^{2}\right)\end{array}$ \\
\hline \multirow{3}{*}{ K250 } & 7 & 3 & $\begin{array}{c}12.34 \\
12.52 \\
12.445\end{array}$ & $\begin{array}{l}20 \\
28 \\
23\end{array}$ & $\begin{array}{l}113.23 \\
158.53 \\
130.22\end{array}$ & 133.99 \\
\hline & 14 & 3 & $\begin{array}{c}12.53 \\
12.535 \\
12.715\end{array}$ & $\begin{array}{l}28 \\
30 \\
28\end{array}$ & $\begin{array}{l}158.53 \\
169.85 \\
158.53\end{array}$ & 162.30 \\
\hline & 28 & 3 & $\begin{array}{l}12.715 \\
12.635 \\
12.465\end{array}$ & $\begin{array}{l}38 \\
47 \\
37\end{array}$ & $\begin{array}{l}215.15 \\
266.10 \\
209.48\end{array}$ & 230.24 \\
\hline
\end{tabular}

Tabel 4. Hasil Uji Kuat Lentur Balok Beton Dilakukan di Laboratorium Uji Beton S1 Teknik Sipil, FTSP - ITS

\begin{tabular}{|c|c|c|c|c|c|c|c|c|}
\hline $\begin{array}{l}\mathrm{P} \\
(\mathrm{L}) \\
\mathrm{Cm}\end{array}$ & $\begin{array}{l}\mathrm{L} \\
\text { (b) } \\
\mathrm{cm}\end{array}$ & $\begin{array}{l}\mathrm{T} \\
(\mathrm{t}) \\
\mathrm{cm}\end{array}$ & $\begin{array}{c}\text { Gaya } \\
\text { Lentur } \\
\text { (P) } \\
\text { kg }\end{array}$ & $\begin{array}{c}\text { Momen } \\
\text { Perlawanan } \\
\text { Penampang } \\
(\mathrm{w}) \\
\mathrm{cm}^{3}\end{array}$ & $\begin{array}{c}\text { Jarak } \\
\text { Perletakan } \\
\text { (Lo) } \\
\text { cm }\end{array}$ & $\begin{array}{c}\text { Momen } \\
\text { Lentur } \\
(M) \\
\text { kgm }\end{array}$ & $\begin{array}{c}\text { Tegangan } \\
\text { Lentur } \\
\text { (olt) } \mathrm{kg} / \mathrm{cm}^{2}\end{array}$ & $\begin{array}{c}\text { Berat } \\
\text { Kering } \\
(\mathrm{kg})\end{array}$ \\
\hline 100 & 20 & 40 & 22.450 & $5.333,333$ & 80 & 4.490 & 84,19 & 194,22 \\
\hline
\end{tabular}

\section{KESIMPULAN}

Dari hasil pengamatan serta analisa yang telah diuraikan dalam bab sebelumnya, dapat disimpulkan beberapa hal antara lain sebagai berikut:

1. Kuat tarik pilinan Bambu Apus ratarata adalah 1.989,97 kg/ $\mathrm{cm}^{2}$. Bambu Apus memiliki kuat tarik rata-rata terbesar. Kuat tarik pilinan bambu jenis ini kurang dari tegangan leleh baja tulangan mutu U-22, yaitu 2.200 $\mathrm{kg} / \mathrm{cm}^{2}$. Kuat tarik pilinan bambu ini lebih kecil 9,55 \% dari yang diharapkan.

2. Kuat tekan silinder umur 28 hari sebesar $230,24 \mathrm{~kg} / \mathrm{cm}^{2}$ memenuhi kuat tekan rencana, yaitu $225 \mathrm{~kg} / \mathrm{cm}^{2}$. Kuat tekan silinder umur 28 hari lebih besar $2,328 \%$ dari kuat tekan rencana.
3. Bambu dapat digunakan sebagai pengganti baja ditinjau dari korelasi perbedaan modulus elastisitas antara baja dengan bambu yang hanya terpaut $10 \%$.

4. Gaya lentur yang dihasilkan dari balok bertulangan pilinan bambu apus lebih besar $75,49 \%$ dari

hasil perhitungan balok normal secara teoristis menggunakan tegangan baja, dan lebih besar 93,34\% dibandingkan hasil perhitungan balok normal teoritis dengan tegangan bambu.

Momen yang dihasilkan dari balok bertulangan pilinan bambu apus lebih besar 39,33\% dari hasil perhitungan balok normal secara teoritis dengan tegangan baja. Lebih besar 53,39\% dari hasil Perhitungan balok normal secara teoritis dengan tegangan bambu. 


\section{SARAN}

1. Agar kuat tarik/tegangan pilinan bambu dapat lebih seragam, dimungkinkan pembuatan alat/mesin yang dapat memproduksi helaian bambu bagian kulit dan alat/mesin yang dapat memilin bambu secara seragam, efisien dan efektif.

2. Benda uji balok seharusnya dibuat paling tidak tiga benda uji. Tetapi dikarenakan keterbatasan biaya, pada penelitian ini hanya dibuat satu benda uji.

3. Di dalam membuat permodelan balok disarankan agar menyesuaikan dengan kondisi, dalam hal ini berat balok beton, agar mobilisasi saat pengujian menjadi mudah.

4. Pengujian terhadap kuat tarik bambu diusahakan lebih banyak variasi dalam jumlah pilinan bambu

\section{DAFTAR PUSTAKA}

[1] Pathurahman, Fajrin, Jauhar, dan Kusuma, Dwi Anggraini, September 2003. Aplikasi Bambu Pilinan Sebagai Tulangan Balok Beton, < URL:http://puslit.petra.ac.id/journal s/civil >

[2] Krisdianto, Sumarni, Ginuk, dan Ismanto, Agus, 2007. Sari Hasil Penelitian Bambu, <URL:http://www.dephut.go.id/INFO RMASI/litbang/teliti/bambu.htm>

[3] Rochman, Abdul, April 2005. "Peningkatan Kinerja Tulangan Bambu pada Balok Beton Bertulang dengan Cara Perbaikan Kuat Lekat". Jurnal Teknik Gelagar Vol. 16, No. 01, April 2005 : 1 -970

[4] SII. 0052 - 80 ( Mutu dan Cara Uji Agregat Beton )

[5] Anonim, 1971. Peraturan Beton Bertulang Indonesia 1971. Jakarta : Direktorat Penyelidikan Masalah Bangunan Departemen Pekerjaan Umum dan Tenaga Listrik.

[6] SNI 03 - 2847 - 2002 ( Tata Cara Perhitungan Struktur Beton untuk Bangunan Gedung ) 